\title{
Relationship Between Emotional Processing, Drinking Severity and Relapse in Adults Treated for Alcohol Dependence in Poland
}

\author{
Maciej Kopera ${ }^{1}$, Andrzej Jakubczyk ${ }^{1, *}$, Hubert Suszek ${ }^{2}$, Jennifer M. Glass ${ }^{3}$, Anna Klimkiewicz ${ }^{1}$, Anna Wnorowska ${ }^{1}$, \\ Kirk J. Brower ${ }^{3}$ and Marcin Wojnar ${ }^{1,3}$ \\ ${ }^{1}$ Department of Psychiatry, Medical University of Warsaw, 27 Nowowiejska St, Warsaw, Poland, ${ }^{2}$ Faculty of Psychology, University of Warsaw, \\ Warsaw, Poland and ${ }^{3}$ Department of Psychiatry, Addiction Research Center, University of Michigan, Ann Arbor MI, USA \\ *Corresponding author: Department of Psychiatry, Medical University of Warsaw, 27 Nowowiejska St., Warsaw 00-665, Poland. \\ Tel.: +48-22-825-1236; Fax: +48-22-825-1315; E-mail: ajakubczyk@ wum.edu.pl
}

(Received 18 June 2014; first review notified 1 September 2014; in revised form 11 October 2014; accepted 8 December 2014)

\begin{abstract}
Aims: Growing data reveals deficits in perception, understanding and regulation of emotions in alcohol dependence (AD). The study objective was to explore the relationships between emotional processing, drinking history and relapse in a clinical sample of alcohol-dependent patients. Methods: A group of 80 inpatients entering an alcohol treatment program in Warsaw, Poland was recruited and assessed at baseline and follow-up after 12 months. Baseline information about demographics, psychopathological symptoms, personality and severity of alcohol problems was obtained. The Schutte Self-Report Emotional Intelligence (EI) Test and Toronto Alexithymia Scale (TAS) were utilized for emotional processing assessment. Follow-up information contained data on drinking alcohol during the last month. Results: At baseline assessment, the duration of alcohol drinking was associated with lower ability to utilize emotions. Patients reporting more difficulties with describing feelings drank more during their last episode of heavy drinking, and had a longer duration of intensive alcohol use. A longer duration of the last episode of heavy drinking was associated with more problems identifying and regulating emotions. Poor utilization of emotions and high severity of depressive symptoms contributed to higher rates of drinking at follow-up. Conclusions: These results underline the importance of systematic identification of discrete emotional problems and dynamics related to AD. This knowledge has implications for treatment. Psychotherapeutic interventions to improve emotional skills could be utilized in treatment of alcohol-dependent patients.
\end{abstract}

\section{INTRODUCTION}

Emotional processing deficits are important factors in the development and course of alcohol dependence (AD) (e.g. OscarBerman and Bowirrat, 2005; Volkow et al., 2012). Perception, understanding and regulation of emotional experience interface with higher-level cognitive functions (cognitive set switching, response inhibition, decision making) in behaviors responding to incentives. It is thought that alcohol-dependent individuals might use alcohol as a mechanism to regulate one's affective experience (Lang et al., 1999), and this pathological coping mechanism may in turn lead to relapse (Moos and Moos, 2006).

Some aspects of emotional processing have been selectively studied in relation to $\mathrm{AD}$. One of them is alexithymia, a multifaceted construct characterized by difficulties in identifying and describing one's own feelings, impoverished inner emotional and fantasy life, and a concrete, reality-based cognitive style (Taylor et al., 1997). These characteristics have been shown to appear in 45-67\% of alcohol-dependent patients (Thorberg et al., 2009) and may possibly predispose to AD development (Parker et al., 1989). AD patients whose scores on a self-report scale indicated alexithymia had a significantly younger age of onset and longer duration of problem drinking, greater alcohol consumption and significantly higher Michigan Alcohol Screening Test (MAST) scores compared to patients without alexithymia (e.g. Kauhanen et al., 1992; Uzun et al., 2003). Despite such strong theoretical background, only two studies to date showed that alexithymia was a predictor of poor outcomes in alcohol-dependent patients (Ziolkowski et al., 1995; Loas et al., 1997), and only one was a prospective study that included a control measure of negative affectivity. Accordingly, available literature reviews (Thorberg et al., 2009) suggest that there is still not enough evidence to consider alexithymia a vulnerability factor in the development and maintenance of alcohol use disorders.
Several theories attribute regulation of negative affect (NA) as a distinctive cause for alcohol consumption (Levenson et al., 1980; Colder and Chassin, 1993; Khantzian, 1997). Even though it is suggested that no single personality trait or constellation of traits consistently predicts $\mathrm{AD}$, an indirect effects are postulated for neuroticism and extraversion, personality traits that are related and correspond respectively to negative and positive affectivity (Sher et al., 1999). Numerous studies have shown that self-reported negative mood predicts higher rates of relapse (e.g. Hodgins et al., 1995; Cooney et al., 1997) and most relapses occur during a state of NA (Hartka et al., 1991). In addition, individuals with substance use disorders and comorbid affective disorders have worse treatment outcomes (Hodgins et al., 1999; Curran et al., 2000; Conner et al., 2005; Kodl et al., 2008).

Research findings indicate that deficits in verbal and nonverbal emotion recognition associated with alexithymic characteristics may be linked particularly to negative emotions (Lane et al., 2000; Parker et al., 2005). Other studies show that alcohol-dependent patients demonstrate deficits in accurately labeling emotions exhibited by unimodal auditory or visual stimuli (e.g. Philippot et al., 1999; Kornreich et al., 2001a,b; Maurage et al., 2009, 2011) and crossmodal (faces and voices; Maurage et al., 2007) emotional stimuli. The same studies also show they overestimate the emotional intensity of affective stimuli compared with normal controls.

Finally, difficulties in identification and description of one's own emotional experience, together with impairments in perception and labeling of emotion displayed by others, may represent a broadly based emotion-processing deficit. These competencies are implied as one of the basic constituents of emotional intelligence (EI). Currently, EI is conceptualized as a set of emotional competencies such as recognition, understanding, regulation and utilization of emotions in thinking or acting (Matthews et al., 2007). Theoretical approaches to EI 
focus on specific abilities measured via maximum-performance tests (Mayer et al., 2002) or emotion-related dispositions and self-perceptions measured via self-report (e.g. Schutte et al., 1998). Low EI could possibly lead to problem drinking, due to an inherent inability to manage NA, difficulties in interpersonal relations that lead to NA, and at least in youths, lack of socioemotional skills that help them resist peer pressure (Peterson et al., 2011). Lower EI was related to higher alcohol use in adolescents (Trinidad and Johnson, 2002) and lower trait EI was a significant predictor of alcohol-related problems in non-treated adults (Riley and Schutte, 2003). Even though current data show a negative association between EI and level of alcohol consumption or alcohol-related problems in non-clinical populations, this association in clinical populations still needs to be explored (Kun and Demetrovics, 2010; Peterson et al., 2011).

Together, these various views underline the importance of assessing emotional processing in AD patients. Difficulties in emotional decoding and alexithymia may be part of a more general deficit in EI observed in this population, giving the conceptual frame for research on emotional processing in alcoholism. Low EI could possibly manifest as an inability to manage NA or difficulties in interpersonal relations and socioemotional skills that lead to NA, thus increasing the risk for using alcohol as a coping mechanism (Moos and Moos, 2006). More severe deficits in perceiving emotions were found in patients who dropped out from treatment (Foisy et al., 2007). Importantly, Kornreich et al. (2002) showed that interpersonal difficulties serve as a mediator between emotional decoding accuracy and AD. These results support the view that inhibition of the automatic emotional response needs to be exercised in $\mathrm{AD}$ patients, and underline the importance of emotion management training for the prevention of relapse in AD patients. CBT-based treatments for AD might additionally be supplemented by interventions focused on developing emotional skills, such as mindfulness-based relapse prevention (Bowen et al., 2009; Witkiewitz et al., 2013).

Therefore, the objective of our prospective study was to investigate the relationships between emotional processing, drinking history and relapse in a clinical sample of alcohol-dependent patients. Specifically, we aimed at assessing the associations between EI, alexithymia and alcohol use as well as drinking consequences and to control for the influence of the previously recognized factors of relapse (e.g. NA, personality components). We anticipated that poor EI and high alexithymia would be associated with more severe alcohol drinking and greater risk for relapse in $\mathrm{AD}$ patients.

\section{MATERIALS AND METHODS}

\section{Participants}

A group of 80 inpatients entering an alcohol treatment program in Warsaw, Poland, was recruited into the study. The 8-week abstinence-based inpatient treatment program combined intensive group and individual therapy as well as elements of 12-step facilitation and relapse prevention. Participation in the study was voluntary. Written informed consent was obtained from all participants. The study was approved by both the Medical Institutional Review Board at the University of Michigan and the Bioethics Committee at the Medical University of Warsaw. All patients enrolled in the study fulfilled the DSM-IV criteria for AD. Patients with active withdrawal symptoms were excluded from the study. Participants were screened for Axis I psychiatric comorbidities using clinical observations and the MINI International Neuropsychiatric Interview (Masiak and Przychoda, 1998; Sheehan et al., 1998). All study subjects with another Axis I diagnosis (excluding tobacco dependence) were excluded from the study. In addition, patients with marked cognitive deficits (scores of 25 or less on the MiniMental State Examination) (Folstein et al., 1975) were not eligible for the study. The baseline assessment was performed before initiation of the treatment. During the assessment, selfreport questionnaires were collected. At 1 year after finishing the inpatient treatment program, alcohol-dependent patients and if possible their family members, were interviewed in person or by phone, and screened for drinking in the last month (relapse). Assessment of the 30-days period instead of one year between the baseline and follow-up assessments was considered much more reliable as it reflects a period of time, which is relatively easy to recall. If contact with the patient was not possible, family members remained the only source of the information. The relapse was confirmed if either the patient or the family member reported drinking. If neither the patient nor the family could be contacted, then the patient's data was not included in the follow-up analyses $(n=8)$.

\section{Measures}

1. The severity of AD was assessed using the Michigan Alcoholism Screening Test (MAST; Selzer, 1971), Short Inventory of Problems (SIP; Alterman et al., 2009) and a single question from the modified version of the Substance Abuse Outcomes Module (Smith et al., 1996) asking about the age at onset of drinking problems throughout the life. The duration of problem drinking was defined here as the difference in age at the baseline assessment and the age when problems related to drinking began. The Substance Abuse Outcomes Module assessed alcohol and other substance use over the past 4 weeks prior to the baseline assessment. The Alcohol Timeline Follow-Back (Sobell et al., 1988) interview was used to quantify how many days a patient drank alcohol during the 3 months prior to baseline assessment.

2. The Toronto Alexithymia Scale (TAS-20) was used as a self-report measure of alexithymia. The scale includes a total score $\left(\mathrm{TAS}_{\mathrm{T}}\right)$ and three component scores, representing different aspects of the measured construct: (1) difficulty identifying feelings $\left(\mathrm{TAS}_{\mathrm{DIF}}\right)$; (2) difficulty describing feelings (TAS $\mathrm{DDF}_{\mathrm{DD}}$; and (3) externally oriented thinking $\left(\mathrm{TAS}_{\mathrm{EOT}}\right.$ ) (Taylor et al., 1985; Cedro et al., 2001).

3. The Schutte Self-Report Emotional Intelligence Test (SSEIT) is a self-report measure of EI, based on the theoretical model introduced by Salovey and Mayer (1990). In this model EI is conceptualized as a composite of several emotional skills such as perception, appraisal and expression of emotion; emotional facilitation of thinking; understanding, analyzing and employing emotional knowledge; and reflective regulation of emotions to further emotional and intellectual growth (Schutte et al., 1998; Jaworowska et al., 2005). Current data, the factor structure of SSEIT, the most consistently reported four-factor model has been applied. The factors were calculated and named according to Saklofske et al. (2003), and match those described 
by Petrides and Furnham (2000): Optimism/Mood Regulation $\left(\operatorname{SSEIT}_{\mathrm{R}}\right)$, Appraisal of Emotions $\left(\mathrm{SSEIT}_{\mathrm{A}}\right)$, Utilization of Emotions (SSEIT ${ }_{\mathrm{U}}$ ) and Social Skills $\left(\mathrm{SSEIT}_{\mathrm{S}}\right)$.

4. Social support was assessed using the Medical Outcomes Study Social Support Survey (MOSSSS; Sherbourne and Stewart, 1991).

5. The subscale scores for anxiety $\left(\mathrm{BSI}_{\mathrm{Anx}}\right)$ and depression $\left(\mathrm{BSI}_{\text {Dep }}\right.$ ) from the Brief Symptom Inventory (BSI) (Derogatis and Melisaratos, 1983) were included measures of current NA.

6. The NEO Five-Factor Inventory (NEO-FFI), was used to assess the five major personality domains to control for trait negative and positive emotionality (Costa and McCrae, 1992; Zawadzki et al., 1998). Analyses utilized raw scores for Neuroticism $\left(\mathrm{NEO}_{\text {Neuroticism }}\right)$, Extraversion ( $\left.\mathrm{NEO}_{\text {Extraversion }}\right)$ Agreableness ( $\left.\mathrm{NEO}_{\text {Agreableness }}\right)$, Conscientiousness $\left(\mathrm{NEO}_{\text {Contientiousness }}\right)$ and Openness ( $\left.\mathrm{NEO}_{\text {Openness }}\right)$.

\section{Data analysis}

Normality distribution of the data was assessed with Kolmogorov-Smirnov test. In case of non-normal distribution of the variable, logarithmic transformation was performed. The association between the control measures $\left(\mathrm{BSI}_{\mathrm{Anx}}\right.$, $\mathrm{BSI}_{\text {Dep, }}, \quad \mathrm{NEO}_{\text {Neuroticism }}, \quad \mathrm{NEO}_{\text {Extraversion }}, \quad \mathrm{NEO}_{\text {Agreableness }}$, $\mathrm{NEO}_{\text {Contientiousness }}, \mathrm{NEO}_{\text {Openness }}, \mathrm{MOSSSS}$ ), as well as the influence of age, gender and education, was explored systematically using correlation or analysis of variance (ANOVA), and when relevant included as covariates in the further analyses.

In order to determine the most significant correlates of drinking history at baseline, relevant variables were included in the linear regression analyses. ANOVA was performed to compare AD subjects dichotomized at follow-up, by the presence or absence of drinking in the last month, on EI, alexithymia and relevant control measures. Subsequently, the logistic regression model was applied to predict return to drinking at 1 year, including the variables that previously appeared to differentiate between groups. Only significant interactions are reported. The Bonferroni correction was applied for all multiple comparisons when relevant. The criterion for statistical significance in all tests (two-tailed) was $P<0.05$. The data were analyzed using statistical package SPSS 21.0 for Windows.

\section{RESULTS}

All patients were Caucasian, with $30 \%$ female, a mean (SD) age of $44.81 \pm 10.73$ and a mean education level of 12 years (the last level of secondary school in Poland). The mean duration of alcohol problems before entering treatment was $18.51 \pm 10.64$ years on average, and the duration of their last abstinence period was $42.01 \pm 27.83$ days. The median duration of the last heavy drinking episode was $14(7,43)$ days, and the amount of alcohol consumed during the episode was $40(28,40)$ standard drinks (10 gram per drink). The selfreported severity of depressive and anxiety symptoms was $0.98 \pm 0.89$ and $0.69 \pm 0.68$, respectively. Follow-up data were available for 71 subjects $(88.8 \%)$, among which $26 \%$ relapsed and $74 \%$ reported sobriety during the previous month.

\section{Relationship between severity of drinking, emotional} intelligence and alexithymia

Correlations between drinking history measures at baseline, EI and alexithymia are presented in Table 1. Those variables which correlated significantly with duration of problem drinking and maximum amount of alcohol consumed daily during last episode of heavy drinking were included as controls in the further analyses.

Analyses revealed that patients with longer duration of the last heavy drinking episode were characterized by less effective emotion regulation $\left(\mathrm{SSEIT}_{\mathrm{R}} ; r=-0.26 ; P=0.02\right)$, as well as greater difficulties with identifying feelings $\left(\mathrm{TAS}_{\mathrm{DIF}} ; r=\right.$ $0.26 ; P=0.02)$ and generally higher $\mathrm{TAS}_{\mathrm{T}}$ scores $(r=0.24$; $P=0.04)$. Lower emotion utilization skills $\left(\mathrm{SSEIT}_{\mathrm{U}}\right)$ were observed among patients who reported more drinking days in the last month $(r=-0.34 ; P=0.003)$ and the last three months $(r=-0.25 ; P=0.04)$, as well as younger age at onset of problem drinking $(r=0.23 ; P=0.04)$. Problem drinking duration was associated with the total alexithymia score as well as two of its subscales (Table 1). Other factors that were associated with problem drinking duration were age and sex, older age $(r=0.56 ; P<0.001)$ and male gender $(\mathrm{F}=7.94 ; P=0.006)$. After adjusting for age (beta $=0.55, P<0.001$ ) and gender (beta $=-0.33, P<0.001$ ) in the linear regression model, high TAS $_{\text {DDF }}$ (beta $=0.21, P=0.02$ ) remained an independent correlate of problem drinking duration.

Moreover, the maximum amount of alcohol consumed daily during the last episode of heavy drinking was negatively correlated with age $(r=-0.27 ; P=0.02)$. As expected, men consumed significantly more alcohol than women $(\mathrm{M}=41.18 \pm 18.50$ vs $\mathrm{M}=31.48 \pm 17.89 ; \mathrm{F}=2.29 ; P=0.03)$. In the linear regression model, after adjustment for age (beta $=-0.30 ; P=0.005)$ and gender (beta $=-0.26 ; P=0.02$ ), alexithymia $\left(\mathrm{TAS}_{\mathrm{T}}\right.$ ) remained a significant correlate of higher daily alcohol intake during last episode of heavy drinking (beta $=0.31 ; P=0.004$ ).

\section{Relationship between emotional intelligence, alexithymia and relapse to drinking}

Results of the preliminary ANOVA analysis of drinking at follow-up are presented in Table 2. When corrected for multiple comparisons (Bonferroni correction: $P<0.002$ ) only $\mathrm{BSI}_{\text {Dep, }}$

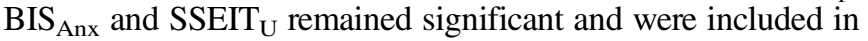
the following logistic regression analysis. After controlling for age and gender, severity of depressive symptoms at baseline $(\mathrm{OR}=3.22$; 95\% CI: $1.04-9.93 ; P=0.04)$ and emotion utilization $(\mathrm{OR}=0.63$; 95\% CI: $0.44-0.89 ; P=0.01)$ remained significant predictors of relapse. The model was significant (chi square $=21.73$, df $=3, P<0.0005$ ) with $39 \%$ of the variance explained $($ Nagelkerke R square $=0.39)($ Table 3$)$.

\section{DISCUSSION}

In the present study, a distinctive set of the self-reported emotional characteristics was analyzed in a group of inpatients being treated for AD. According to the objectives of the study, associations between emotional processing and drinking history were explored. Models involving selected facets of emotion processing were also included as the predictors of relapse in the month preceding follow-up at 1 year. 
Table 1. Correlations between baseline drinking history measures, emotional intelligence (SSEIT) and alexithymia (TAS) factors

\begin{tabular}{|c|c|c|c|c|c|c|c|c|}
\hline & SSEIT $_{\mathrm{R}}$ & SSEIT $_{\mathrm{A}}$ & SSEIT $_{U}$ & SSEIT $_{\mathrm{S}}$ & $\mathrm{TAS}_{\mathrm{T}}$ & $\mathrm{TAS}_{\mathrm{DDF}}$ & $\mathrm{TAS}_{\mathrm{DIF}}$ & $\mathrm{TAS}_{\mathrm{EOT}}$ \\
\hline MAST total score & -0.03 & 0.07 & -0.06 & -0.21 & 0.05 & 0.04 & 0.07 & -0.02 \\
\hline Duration of abstinence & 0.22 & 0.06 & 0.18 & 0.13 & 0.04 & 0.22 & 0.03 & -0.07 \\
\hline Number of standard drinks ( 3 months) & -0.03 & -0.02 & -0.17 & 0.06 & 0.08 & -0.01 & 0.04 & 0.11 \\
\hline Number of days drinking ( 3 months) & -0.13 & -0.08 & $-0.25^{*}$ & -0.09 & -0.04 & -0.07 & -0.05 & -0.01 \\
\hline Number of days drinking (28 days) & -0.20 & 0.06 & $-0.34^{*}$ & 0.04 & 0.17 & 0.04 & 0.08 & 0.22 \\
\hline Number of drinks per drinking day (3 months) & 0.21 & 0.06 & 0.16 & 0.17 & 0.18 & 0.15 & 0.09 & 0.18 \\
\hline Age at onset of problems from dinking & 0.17 & 0.01 & $0.23 *$ & $0.25^{*}$ & -0.18 & -0.21 & $-0.25 *$ & 0.03 \\
\hline Years of intensive alcohol use & 0.10 & 0.09 & 0.04 & 0.11 & $0.32 * *$ & $0.26^{*}$ & 0.22 & $0.24 *$ \\
\hline Age at first intoxication & 0.22 & -0.26 & 0.14 & $0.39 *$ & -0.20 & -0.22 & -0.17 & -0.08 \\
\hline Duration of the last episode of heavy drinking ${ }^{\mathrm{a}}$ & $-0.26^{*}$ & 0.03 & -0.22 & -0.09 & $0.24^{*}$ & 0.170 & $0.26^{*}$ & 0.09 \\
\hline Maximum amount of alcohol daily during last episode of heavy drinking ${ }^{\mathrm{a}}$ & -0.12 & 0.03 & -0.04 & -0.05 & $0.29 *$ & $0.27 *$ & $0.27 *$ & 0.16 \\
\hline
\end{tabular}

$\mathrm{SSEIT}_{\mathrm{R}}$, optimism/mood regulation; $\mathrm{SSEIT}_{\mathrm{A}}$, appraisal of emotions; $\mathrm{SSEIT}_{\mathrm{U}}$, utilization of emotions; $\mathrm{SSEIT}_{\mathrm{S}}$, social skills; TAS $_{\mathrm{T}}$, total score; TAS $_{\mathrm{DDF}}$, difficulty describing feelings; $\mathrm{TAS}_{\mathrm{DIF}}$, difficulty identifying feelings; $\mathrm{TAS}_{\mathrm{EOT}}$, externally oriented thinking.

$* P<0.05$.

$* * P<0.001$.

${ }^{\mathrm{a} C}$ Common logarithm of the values.

Table 2. Comparison between patients who resumed drinking and maintained abstinence after alcohol treatment (ANOVA)

\begin{tabular}{|c|c|c|c|}
\hline & \multicolumn{2}{|l|}{ Mean (SD) } & \multirow[b]{2}{*}{$P$} \\
\hline & $\begin{array}{l}\text { Abstinent } \\
(n=52)\end{array}$ & $\begin{array}{l}\text { Non-abstinent } \\
(n=19)\end{array}$ & \\
\hline Age & $45.12(10.96)$ & $43.74(10.58)$ & 0.64 \\
\hline Education & $12.52(2.76)$ & $12.00(3.39)$ & 0.53 \\
\hline Gender (male/female) & $35 / 17$ & $14 / 5$ & $0.77^{\mathrm{a}}$ \\
\hline $\mathrm{NEO}_{\text {Neuroticism }}$ & $25.02(7.53)$ & $27.63(7.83)$ & 0.21 \\
\hline $\mathrm{NEO}_{\text {Extraversion }}$ & $25.29(6.64)$ & $22.74(7.61)$ & 0.17 \\
\hline $\mathrm{NEO}_{\text {Agreableness }}$ & $27.96(4.82)$ & $27.79(4.94)$ & 0.89 \\
\hline $\mathrm{NEO}_{\text {Contientiousness }}$ & $28.37(6.97)$ & $28.53(6.23)$ & 0.93 \\
\hline $\mathrm{NEO}_{\text {Openness }}$ & $26.57(5.66)$ & $24.89(5.99)$ & 0.28 \\
\hline MOSSSS & $60.02(17.93)$ & $56.71(16.51)$ & 0.49 \\
\hline Severity of anxiety symptoms & $0.55(0.55)$ & $1.12(0.80)$ & 0.001 \\
\hline $\begin{array}{l}\text { Severity of depressive } \\
\text { symptoms }\end{array}$ & $0.74(0.72)$ & $1.65(1.02)$ & 0.001 \\
\hline $\operatorname{SSEIT}_{R}$ & $37.69(5.01)$ & $34.45(6.29)$ & 0.03 \\
\hline SSEIT $_{\mathrm{A}}$ & $19.24(3.51)$ & $19.05(3.15)$ & 0.83 \\
\hline SSEIT $_{U}$ & $15.35(1.69)$ & $13.31(2.54)$ & 0.0003 \\
\hline SSEIT $_{S}$ & $18.06(2.81)$ & $17.53(2.41)$ & 0.47 \\
\hline $\mathrm{TAS}_{\mathrm{T}}$ & $64.80(9.62)$ & $65.37(8.38)$ & 0.82 \\
\hline $\mathrm{TAS}_{\mathrm{DDF}}$ & $16.35(2.58)$ & $15.47(2.59)$ & 0.21 \\
\hline TAS $_{\text {DIF }}$ & $22.20(4.96)$ & $23.89(4.62)$ & 0.20 \\
\hline $\mathrm{TAS}_{\mathrm{EOT}}$ & $26.24(5.30)$ & $26.00(3.14)$ & 0.85 \\
\hline
\end{tabular}

$\mathrm{SSEIT}_{\mathrm{R}}$, optimism/mood regulation; $\mathrm{SSEIT}_{\mathrm{A}}$, appraisal of emotions; $\mathrm{SSEIT}_{\mathrm{U}}$ utilization of emotions; SSEIT $_{\mathrm{S}}$, social skills; TAS $_{\mathrm{T}}$, alexithymia total score TAS $_{\mathrm{DDF}}$, difficulty describing feelings; $\mathrm{TAS}_{\mathrm{DIF}}$, difficulty identifying feelings; $\mathrm{TAS}_{\mathrm{EOT}}$, externally oriented thinking.

${ }^{\mathrm{a} C h i}$ square test.

\section{Emotional processing and relapse}

To our knowledge, this is the first prospective study where the association between different facets of self-reported EI and relapse were analyzed prospectively in a clinical sample of $\mathrm{AD}$ patients. We observed that better utilization of emotions was a protective factor for relapse. To date, the relationship between self-reported EI and drinking outcomes has been investigated mostly in non-clinical populations, suggesting that lower EI is associated with higher alcohol consumption (for rev., Kun and Demetrovics, 2010; Peterson et al., 2011). Hypothetically low EI could lead to problem drinking via the inability to manage NA (Khantzian, 2003) or interpersonal difficulties that trigger NA (Austin et al., 2005). According to the model of relapse proposed by Marlatt and Witkiewitz (e.g.
Table 3. Logistic regression model predicting relapse after alcohol treatment

\begin{tabular}{llll}
\hline & \multicolumn{2}{l}{ Model } & \\
\cline { 2 - 3 } & OR & $95 \%$ CI & $P$ \\
\hline Severity of depressive symptoms & 3.22 & $1.04-9.93$ & 0.04 \\
Severity of anxiety symptoms $_{\text {SSEIT }}$ & 1.13 & $0.29-4.42$ & 0.86 \\
Age & 0.63 & $0.44-0.89$ & 0.01 \\
Gender & 1.02 & $0.96-1.09$ & 0.47 \\
& 2.80 & $0.51-15.40$ & 0.23 \\
& chi square $=23.66 ; \mathrm{df}=5 ;$ & \\
\hline
\end{tabular}

95\% CI, 95\% confidence interval; SSEIT $_{\mathrm{U}}$, utilization of emotions.

2005), relapse is expected when at-risk individuals are confronted with high-risk situations, for which adequate coping strategies are insufficient. Hitherto, NA has been revealed as one of the significant relapse predictors. AD individuals with the concomitant affect-related disorders (anxiety or depression) have been shown to relapse more often (for rev., Bradizza et al., 2006), and retrospectively to report that relapse occurred in the context of NA (e.g. Zywiak et al., 1996). The results from the current study, showing that the severity of self-reported depressive symptoms contributed to relapse, are therefore consistent with the previous reports.

It has been postulated that emotional dysregulation is a significant predictor of alcohol and drug use disorders, beyond the influence of NA itself (Bradley et al., 2011). Though, the importance of the positive affect (PA) as the constituent of the coping resources has been underlined. It is thought that PA enhances people's cognitions and actions through increasing psychological resources and cognitive flexibility (Fredrickson and Levenson, 1998) in a way that is essential for establishing personal and social competences (e.g. Lyubomirsky et al., 2005). Importantly, the association between self-reported EI and PA was stronger than with the NA (e.g. Gallagher and Vella-Brodrick, 2008; Kafetsios and Zampetakis, 2008; Mikolajczak et al., 2008). Kong et al. (2012) found that subjects with higher levels of trait EI, experience less NA and more PA, which mediated a decrease in their mental distress. In a large sample of AD outpatients, McHugh et al. (2013) found that the association between stress and NA is weaker in those patients who reported higher levels of PA. Additionally, 
PA was negatively associated with the level of alcohol craving. In the population of AD inpatients analyzed in our study, better utilization of emotions was a protective factor in relapse to drinking. The emotion utilization factor reflects the self-perception of oneself as someone who is able to use positive emotions to facilitate thinking or acting. The higher the score, the more the subject is convinced that his planning or decision making can be reinforced by positive affective state. To the extent that the results of the previous investigations can be applied to the current study, it is plausible that deficits in utilizing positive emotions to build cognitive or motivational resources, leads to ineffective coping strategies and urges to drink alcohol. Thus, patients who reported deficits in the integration of PA with cognitive or behavioral execution were more likely to relapse. It can be further speculated that a disability in experiencing positive emotions-lower PAincreases the likelihood of relapse. Those patients might drink to enhance PA. In a study of non-clinical sample of young adults from the families with high severity of $\mathrm{AD}$, individuals who manifested lower ability to recognize complex emotions presented on faces were more likely to anticipate experiencing arousal/aggression decrease, sexual enhancement and global positive consequences due to alcohol use (Kopera et al., 2008). Interestingly, in experimental study performed on a group of healthy adults (undergraduate psychology students) Walter et al. (2011) observed that those participants who expected receiving alcohol, presented enhanced interpretation of facial expressions as happy, and this finding was independent of the actual alcohol intake. Indeed, a substantial amount of research on the relationship between alcohol expectancies and drinking outcomes reveals that the degree to which individuals expect alcohol to produce a variety of general and specific effects (e.g. social and physical pleasure, social assertiveness, relaxation and tension reduction) is strongly related to drinking outcomes (Jones et al., 2001). Despite involvement of interventions targeting expectancies in various CBT programs, there is still little evidence that they directly lead to changes in post-treatment alcohol consumption. Possibly the influence of alcohol expectancies on treatment outcomes should be conceptualized within more complex models, in concert with other relapse predictors (Witkiewitz and Marlatt, 2004). Hasking and Oei (2008) emphasize the effect of behavioral factors such as individual coping strategies as an influential component of the expectancy framework that enable a better understanding of drinking behavior. Conceivably, assessment of the individual differences in emotional dispositions (like EI) within this framework may contribute to a better understanding of diversity in drinking behavior as well. Contrary to previous reports (Ziolkowski et al., 1995; Loas et al., 1997), yet conformed in studies by de Haan et al. (2012) and Junghanns et al. (2005), we did not find a significant relationship between alexithymia and alcohol treatment outcomes. The mixed results may be partially explained by the differences in methodology, including design and comprehensiveness of drinking measures. Further prospective studies with thorough relapse assessment and control for possible mediating or moderating factors are needed.

\section{Emotional processing and severity of alcohol drinking}

In our study, self-reported frequency of drinking (the number of days drinking) in the last 1 and 3 months, as well as the duration of the last heavy drinking episode was associated with self-reported lower ability to utilize emotions. To our knowledge, this is a novel finding in patients with $\mathrm{AD}$, although a weak association between drinking severity and EI was reported in non-problem drinkers (for rev., Peterson et al., 2011). Lower trait EI was associated with more alcohol use (Austin et al., 2005) and more alcohol-related problems (Riley and Schutte, 2003) in non-addicted individuals.

The association between alexithymia and alcohol consumption has been widely studied, however little research has investigated the underlining mechanisms (for rev., Thorberg et al., 2009). Recent reports revealed that anxious attachment (Thorberg et al., 2011a), or behavior and alcohol expectancy (specifically by the expectancies of affective change and assertion) (Thorberg et al. (2011b) may partially mediate the relationship between alexithymia and craving in AD. Together, the current data suggest that people scoring high in alexithymia use alcohol to feel more confident in social situations, and overcome their emotional difficulties. The lack of emotional awareness, may lead to the experience of unidentified arousal, which is not linked to the emotional cause, especially when more arousal generating negative emotions are involved (Thorberg et al., 2011b).

The results of the current study underline the importance of emotion management training for the prevention of relapse in AD patients. CBT-based treatments for AD could be supplemented by incorporating interventions focused on developing emotional skills. Moreover, interventions such as mindfulnessbased relapse prevention that focus on emotional states and craving may prove especially effective (Bowen et al., 2009; Witkiewitz et al., 2013). It has been recently suggested that CBT-based treatments that incorporate elements of mindfulnessbased training might be effective in treating substance use disorders (Witkiewitz et al., 2005; Bowen et al., 2009). Inhibition of the automatic emotional response is one of the coping skills that needs to be exercised in addicted people, to improve their ability to make self-advantageous decisions in contexts that challenge self-regulatory processes (for rev., Noël et al., 2013).

Although our study provides preliminary evidence on the identification of specific self-reported emotional deficits in $\mathrm{AD}$ patients, the findings should be interpreted with caution. First, because EI and alexithymia were assessed after the development of $\mathrm{AD}$, the causation cannot be inferred. It is not possible to imply that emotional processing deficits pre-date or lead to problematic drinking, the direction of this association might be just opposite. In the other study, with the data coming from a non-clinical sample of young adults (Kopera et al., 2014), it was found that complex emotion perception deficits were not a unique marker of either $\mathrm{AD}$ or high risk for AD. These results provide evidence against the hypothesis that the differences in emotion perception are the consequence of the inherent vulnerability of subjects that may be manifested as they develop $\mathrm{AD}$.

Our definition of relapse is limited. We evaluated drinking 30 days prior to follow-up assessment instead of asking about whole period between baseline and follow-up assessment. We considered this method much more reliable as it reflects a period of time, which is easy to recall. Furthermore, selfreports of alcohol use have been corroborated by objective markers and collateral reports (Whitford et al., 2009). Another limitation is the lack of control group of healthy subjects as 
well as other psychiatric subpopulations to analyze diagnostic group variability.

Even though the validity of the self-reported EI measures has been questioned, and the influence of the current affective state or the social desirability effect may possibly bias the results, it has been revealed that self-reported perception of their own skills by AD individuals, was associated with overconfidence in the evaluation of the ability to abstain from alcohol (e.g. Ferrari et al., 2008). To resolve the direction of the revealed association, a randomized control trial, with the prospective assessment of the effects of EI skills training on drinking outcomes should be introduced. In future studies, ability EI measures, as a complementary assessment, should be used, and predictive validity of trait and ability EI measures should be contrasted. In addition, a model in which the effect of EI on drinking outcomes is mediated by NA should be tested.

Despite these limitations, our study provides evidence for the value of EI research in the field of addiction research. It could lead to the systematic identification of discrete emotional problems and dynamics underlying alcohol use disorders. This knowledge could be used to enhance emotional skills components in relapse prevention therapy. Other studies could address if emotional skills building might prevent alcohol use disorders in individuals with alexithymia and/or low EI, who have other risk factors to develop alcohol use disorders.

Funding - This study was supported by the Polish Ministry of Science and Higher Education grant (DEC-2012/07/B/HS6/02370; 2P05D 004 29), the Fogarty International Center/NIDA International Substance Abuse Research Program grant (D43-TW05818), the Fogarty International Center/NIAAA International Collaborative Alcohol \& Injury Research Training Program grant (D43-TW007569), National Institute on Alcohol Abuse and Alcoholism grant (R21 AA016104).

Conflict of interest statement. All authors declare no conflict of interest.

\section{REFERENCES}

Alterman AI, Cacciola JS, Ivey MA et al. (2009) Reliability and validity of the alcohol short index of problems and a newly constructed drug short index of problems. J Stud Alcohol Drugs 70:304-7.

Austin EJ, Saklofske DH, Egan V. (2005) Personality, well-being and health correlates of trait emotional intelligence. Pers Individ Dif 38:547-58.

Bowen S, Chawla N, Collins S et al. (2009) Mindfulness-based relapse prevention for substance use disorders: a pilot efficacy trial. Subst Abus 30:295-305.

Bradizza CM, Stasiewicz PR, Paas ND. (2006) Relapse to alcohol and drug use among individuals diagnosed with co-occurring mental health and substance use disorders: a review. Clin Psychol Rev 26:162-78.

Bradley B, DeFife J, Guarnaccia C et al. (2011) Emotion dysregulation and negative affect: association with psychiatric symptoms. $J$ Clin Psychiatry 72:685-91.

Cedro A, Kokoszka A, Popiel A. (2001) Alexithymia in schizophrenia: an exploratory study. Psychol Rep 89:95-8.

Colder C, Chassin L. (1993) The stress and negative affect model of adolescent alcohol use and the moderating effects of behavioral under control. J Stud Alcohol 54:326-33.

Conner KR, Sorensen S, Leonard KE. (2005) Initial depression and subsequent drinking during alcoholism treatment. J Stud Alcohol 66:401-6.

Cooney NL, Litt MD, Morse PA et al. (1997) Alcohol cue reactivity, negative-mood reactivity, and relapse in treated alcoholic men. J Abnorm Psychol 106:243-50.

Costa PT, McCrae RR. (1992) NEO PI-R Professional Manual. Odessa, FL: Psychological Assessment Resources Inc.
Curran GM, Flynn HA, Kirchner J et al. (2000) Depression after alcohol treatment as a risk factor for relapse among male veterans. J Subst Abuse Treat 19:259-65.

Derogatis LR, Melisaratos N. (1983) The Brief Symptom Inventory: an introductory report. Psychol Med 13:595-605.

Ferrari J, Groh D, Rulka G et al. (2008) Coming to terms with reality: predictors of self-deception within substance abuse recovery. Addict Disord Their Treat 7:210-8.

Foisy ML, Kornreich C, Fobe A et al. (2007) Impaired emotional facial expression recognition in alcohol dependence: do these deficits persist with midterm abstinence? Alcohol Clin Exp Res 31:404-10.

Folstein MF, Folstein SE, McHugh PR. (1975) 'Mini-mental state'. A practical method for grading the cognitive state of patients for the clinician. J Psychiatr Res 12:189-98.

Fredrickson BL, Levenson RW. (1998) Positive emotions speed recovery from the cardiovascular sequelae of negative emotions. Cogn Emot 12:191-220.

Gallagher EN, Vella-Brodrick DA. (2008) Social support and emotional intelligence as predictors of subjective well-being. Pers Individ Dif 44:1551-61.

De Haan H, Joosten E, Wijdeveld T et al. (2012) Alexithymia is not a stable personality trait in patients with substance use disorders. Psychiatry Res 198:123-9.

Hartka E, Johnstone B, Leino EV et al. (1991) A meta-analysis of depressive symptomatology and alcohol consumption over time. Br J Addict 86:1283-98.

Hasking PA, Oei TPS. (2008) Incorporating coping into an expectancy framework for explaining drinking behaviour. Curr Drug Abuse Rev 1:20-35.

Hodgins DC, el-Guebaly N, Armstrong S. (1995) Prospective and retrospective reports of mood states before relapse to substance abuse. J Consult Clin Psychol 63:400-7.

Hodgins DC, el-Guebaly N, Armstrong S et al. (1999) Implications of depression on outcome from alcohol dependence: a 3-year prospective follow-up. Alcohol Clin Exp Res 23:151-7.

Jaworowska A, Matczak A, Ciechanowicz A et al. (2005) Popularny Kwestionariusz Inteligencji Emocjonalnej (PKIE). Warszawa: Pracownia Testów Psychologicznych PTP.

Jones BT, Corbin W, Fromme K. (2001) A review of expectancy theory and alcohol consumption. Addiction 96:57-72.

Junghanns K, Tietz U, Dibbelt L. (2005) Attenuated salivary cortisol secretion under cue exposure is associated with early relapse. Alcohol Alcohol 40:80-5.

Kafetsios K, Zampetakis LA. (2008) Emotional intelligence and job satisfaction: testing the mediatory role of positive and negative affect at work. Pers Individ Dif 44:712-22.

Kauhanen J, Julkunen J, Salonen JT. (1992) Coping with inner feelings and stress: heavy alcohol use in the context of alexithymia. Behav Med 18:121-6.

Khantzian EJ. (1997) The self-medication hypothesis of substance use disorders: a reconsideration and recent applications. Harv Rev Psychiatry 4:231-44.

Khantzian EJ. (2003) Understanding addictive vulnerability: an evolving psychodynamic perspective. Neuro Psychoanalysis 5:5-21.

Kodl MM, Fu SS, Willenbring ML et al. (2008) The impact of depressive symptoms on alcohol and cigarette consumption following treatment for alcohol and nicotine dependence. Alcohol Clin Exp Res 32:92-9.

Kong F, Zhao J, You X. (2012) Trait emotional intelligence and mental distress: the mediating role of positive and negative affect. Int J Psychol 47:460-6.

Kopera MK, Glass JM, Nigg JT et al. (2008) Theory of mind, early versus late onset of drinking, and alcohol expectancies in young adults. Alcohol Clin Exp Res 32:111A.

Kopera M, Glass JM, Heitzeg MM et al. (2014) Theory of mind among young adult children from alcoholic families. J Stud Alcohol Drugs 75:889-94.

Kornreich C, Blairy S, Philippot P et al. (2001a) Impaired emotional facial expression recognition in alcoholism compared to obsessive compulsive disorder and normal controls. Psychiatry Res. 102: 235-48.

Kornreich C, Blairy S, Philippot P et al. (2001b) Deficits in recognition of emotional facial expression are still present after mid- to long-term abstinence in alcoholics. J Stud Alcohol 62:533-42. 
Kornreich C, Philippot P, Foisy ML et al. (2002) Impaired emotional facial expression is associated with interpersonal problems in alcoholism. Alcohol Alcohol 37:394-400.

Kun B, Demetrovics Z. (2010) Emotional intelligence and addictions: a systematic review. Subst Use Misuse 45:1131-60.

Lane RD, Sechrest L, Reidel RG. (2000) Pervasive emotion recognition deficit common to alexithymia and the repressive coping style. Psychosom Med 62:492-501.

Lang AR, Patrick CJ, Werner GK. (1999) Alcohol and emotional response: multidimensional-multilevel analysis. In Leonard KE, Blane HT (eds). Psychological Theories of Drinking and Alcoholism, 2nd ed. New York: Guilford Press, 328-71.

Levenson RW, Sher KJ, Grossman LM et al. (1980) Alcohol and stress response dampening: pharmacological Effects, expectancy, and tension reduction. J Abnorm Psychol 89:528-38.

Loas G, Fremaux D, Otmani O et al. (1997) Is alexithymia a negative factor for maintaining abstinence? A follow-up study. Compr Psychiatry 5:296-9.

Lyubomirsky S, King L, Diener E. (2005) The benefits of frequent positive affect: does happiness lead to success? Psychol Bull 131:803-55.

Marlatt G, Witkiewitz K. (2005) Relapse prevention for alcohol and drug problems. In Marlatt G, Donovan D (eds). Relapse Prevention: Maintenance Strategies in the Treatment of Addictive Behaviors, 2nd ed. New York: Guilford Press, 1-44.

Masiak M, Przychoda J. (1998) M.I.N.I. Mini International Neuropsychiatric Interview. Polish Version 5.0.0. Lublin: Katedra i Klinika Psychiatrii Akademii Medycznej.

Matthews G, Zeidner M, Roberts RD. (2007) The Science of Emotional Intelligence: Knowns and Unknowns. New York: Oxford University Press.

Maurage P, Campanella S, Philippot P et al. (2007) The crossmodal facilitation effect is disrupted in alcoholism: a study with emotional stimuli. Alcohol Alcohol 42:552-9.

Maurage P, Campanella S, Philippot P et al. (2009) Impaired emotional facial expression decoding in alcoholism is also present for emotional prosody and body postures. Alcohol Alcohol 44:476-85.

Maurage PD, Grynberg X, Noel F et al. (2011) The 'Reading the Mind in the Eyes' test as a new way to explore complex emotions decoding in alcohol dependence. Psychiatry Res 190: 375-8.

Mayer JD, Salovey P, Caruso DR. (2002) Mayer-Salovey-Caruso Emotional Intelligence Test (MSCEIT). User's Manual. Toronto, Ontario, Canada: Multi-Health Systems Inc.

McHugh RK, Kaufman JS, Frost KH et al. (2013) Positive affect and stress reactivity in alcohol-dependent outpatients. J Stud Alcohol Drugs 74:152-7.

Mikolajczak M, Nelis D, Hansenne M et al. (2008) If you can regulate sadness, you can probably regulate shame: associations between trait emotional intelligence, emotion regulation and coping efficiency across discrete emotions. Pers Individ Dif 44:1356-68.

Moos RH, Moos BS. (2006) Rates and predictors of relapse after natural and treated remission from alcohol use disorders. Addiction 101:212-22.

Noël X, Brevers D, Bechara A. (2013) A neurocognitive approach to understanding the neurobiology of addiction. Curr Opin Neurobiol 23:632-8.

Oscar-Berman M, Bowirrat A. (2005) Genetic influences in emotional dysfunction and alcoholism-related brain damage. Neuropsychiatr Dis Treat 1:211-29.

Parker JD, Taylor JG, Bagby RM. (1989) The alexithymia construct: relationship with sociodemographic variables and intelligence. Compr Psychiatry 30:434-41.

Parker PD, Prkachin KM, Prkachin GC. (2005) Processing of facial expressions of negative emotion in alexithymia: the influence of temporal constraint. J Pers. 73:1087-107.

Peterson K, Malouff J, Thorsteinsson EB. (2011) A meta-analytic investigation of emotional intelligence and alcohol involvement. Subst Use Misuse 46:1726-33.

Petrides KV, Furnham A. (2000) On the dimensional structure of emotional intelligence. Pers Individ Dif 29:313-20.

Philippot P, Kornreich C, Blairy S et al. (1999) Alcoholics' deficits in the decoding of emotional facial expression. Alcohol Clin Exp Res 23:1031-8.
Riley H, Schutte NS. (2003) Low emotional intelligence as a predictor of substance-use problems. J Drug Educ 33:391-8.

Saklofske DH, Austin EJ, Minski PS. (2003) Factor structure and validity of a trait emotional intelligence measure. Pers Individ Dif 34:707-21.

Salovey P, Mayer JD. (1990) Emotional intelligence. Imagination Cogn Personal 9:185-211.

Schutte NS, Malouff JM, Hall LE et al. (1998) Development and validation of a measure of emotional intelligence. Pers Individ Dif 25:167-77.

Sheehan DV, Lecrubier Y, Sheehan KH et al. (1998) The Mini-International Neuropsychiatric Interview (M.I.N.I.): the development and validation of a structured diagnostic psychiatric interview for DSM-IV and ICD-10. J Clin Psychiatry 59(Suppl. 20):22-57.

Sher KJ, Trull TJ, Barthlow BD et al. (1999) Personality and alcoholism: issues, methods, and etiological processes. In Leonard KE, Blane HT (eds). Psychological Theories of Drinking and Alcoholism, 2nd ed. New York: Guilford Press, 54-105.

Sherbourne CD, Stewart AL. (1991) The MOS social support survey. Soc Sci Med 32:705-14.

Selzer ML. (1971) The Michigan alcoholism screening test: the quest for a new diagnostic instrument. Am J Psychiatry 127:1653-8.

Smith GR, Ross RL, Rost KM. (1996) Psychiatric outcomes module: Substance abuse outcomes module (SAOM). In Sederer LI, Dickey B (eds). Outcome Assessment in Clinical Practice. Baltimore, MD: Williams and Wilkins, 85-8.

Sobell LC, Sobell MB, Leo GI et al. (1988) Reliability of a timeline method: assessing normal drinkers' reports of recent drinking and a comparative evaluation across several populations. $\mathrm{Br}$ J Addict 83:393-402.

Taylor JG, Ryan D, Bagby RM. (1985) Toward the development of a new self-report alexithymia scale. Psychother Psychosom 44:191-9.

Taylor GJ, Bagby RM, Parker JDA. (1997) Disorders of Affect Regulation: Alexithymia in Medical and Psychiatric Illness. Cambridge: Cambridge University Press.

Thorberg FA, Young RM, Sullivan KA et al. (2009) Alexithymia and alcohol use disorders: a critical review. Addict Behav 34:237-45.

Thorberg FA, Young RM, Sullivan KA et al. (2011a) Alexithymia, craving and attachment in a heavy drinking population. Addict Behav 36:427-30.

Thorberg FA, Young RM, Sullivan KA et al. (2011b) Alexithymia in alcohol dependent patients is partially mediated by alcohol expectancy. Drug Alcohol Depend 116:238-41.

Trinidad DR, Johnson CA. (2002) The association between emotional intelligence and early adolescent tobacco and alcohol use. Pers Individ Dif 32:95-105.

Uzun O, Ates A, Cansever A et al. (2003) Alexithymia in male alcoholics: study in a Turkish sample. Compr Psychiatry 44:349-52.

Volkow ND, Wang GJ, Fowler JS et al. (2012) Addiction circuitry in the human brain. Annu Rev Pharmacol Toxicol 52:321-36.

Walter NT, Mutic S, Markett S et al. (2011) The influence of alcohol intake and alcohol expectations on the recognition of emotions. Alcohol Alcohol 46:680-5.

Whitford JL, Widner SC, Mellick D et al. (2009) Self-report of drinking compared to objective markers of alcohol consumption. Am J Drug Alcohol Abuse 35:55-8.

Witkiewitz K, Marlatt GA. (2004) Relapse prevention for alcohol and drug problems: that was Zen, this is Tao. Am Psychol $\mathbf{5 9}: 224-35$.

Witkiewitz K, Marlatt G, Walker D. (2005) Mindfulness-based relapse prevention for alcohol and substance use disorders. J Cogn Psychother 19:211-28.

Witkiewitz K, Bowen S, Douglas H et al. (2013) Mindfulness-based relapse prevention for substance craving. Addict Behav 38:1563-71.

Zawadzki B, Strelau J, Szczepaniak P et al. (1998) Inwentarz Osobowości NEO-FFI Costy I McCrae. Podręcznik do polskiej adaptacji. Warszawa: Pracownia Testów Psychologicznych PTP.

Ziolkowski M, Gruss T, Rybakowski JK. (1995) Does alexithymia in male alcoholics constitute a negative factor for maintaining abstinence? Psychother Psychosom 63:169-73.

Zywiak WH, Connors GJ, Maisto SA et al. (1996) Relapse research and the reasons for drinking questionnaire: a factor analysis of Marlatt's relapse taxonomy. Addiction 91:121-30. 